\title{
Does forgiveness mediate the impact of school bullying on adolescent mental health?
}

\author{
Estie Janse van Rensburg ${ }^{1, *}$ and Jacques Raubenheimer ${ }^{2}$ \\ ${ }^{1}$ Department of Psychology, University of Pretoria, Humanities Building, 11th Floor, Room 11-23, \\ Lynnwood Road, Pretoria 0002, South Africa \\ ${ }^{2}$ Department of Biostatistics, University of the Free State, PO Box 339, Bloemfontein 9300, South \\ Africa
}

${ }^{*}$ Corresponding author, email: estie.jansevanrensburg@up.ac.za

Objective: The link between both bullying and victimisation and psychopathology has been well established. Forgiveness has been associated with better mental health. However, few studies have examined the relationship between adolescent forgiveness, psychopathology and bullying/ victimisation. This study investigated forgiveness as a mediator of the adverse mental health problems experienced by bullies and victims of bullying.

Method: Participants were 355 Year 10 or Year 11 pupils (age $=14.9$ years) from two British secondary schools in 2007, who completed self-administered measures on bullying and victimisation, mental health, forgiveness of self and others, and forgivingness. The mediating influence of forgiveness on the impact of bullying/victimisation on mental health was tested with a structural equation model.

Results: Data from $55.6 \%$ of the 639 eligible pupils were analysed. Results confirmed an association between bullying/victimisation, forgiveness and psychopathology. Forgiveness scores were found to play a mediating role between bullying/victimisation and psychopathology.

Conclusions: Victimised adolescents who were better able to forgive themselves were more likely to report lower levels of psychopathology, while bullying adolescents who were unable to forgive others were more likely to report higher levels of psychopathology. This suggests a greater role for forgiveness within future research, intervention and policy on bullying. Forgiveness can form a valuable part of preventative and educational anti-bullying programmes.

\section{Introduction}

Bullying and victimisation are serious personal, school and educational problems (Ahmed and Braithwaite 2004, Monks and Coyne 2011) and are frequently experienced by children and adolescents worldwide (Olweus 1991, Smith 2011, Liu et al. 2012). In an international study across 25 countries, Nansel et al. (2004) reported the involvement of bullying at school to range from 9-54\%. Bullying can be defined as "a constellation of behaviours that can be characterized as 1) aggressive or intended to harm, 2) performed repeatedly and over time, and 3) occurring in interpersonal relationships in which a power imbalance exists" (Kim et al. 2006: 1035). Children targeted for peer aggression are variously described as being bullied or victimised (Monks and Coyne 2011). Bullying behaviour can be organised within three categories: direct bullying involving physical aggression (e.g. hitting, kicking or taking belongings-Smith 2011) and verbal bullying (name-calling, teasing in a hurtful way-Monks and Coyne 2011); relational or social bullying are considered indirect bullying and refer to behaviour that occurs behind the person's back where peer relationships 
are manipulated to inflict harm (e.g., social exclusion, gossiping, spreading rumours-Monks and Coyne 2011); and cyber-bullying is performed through media and communications devices (e.g., abusive calls, text messages or emails-Rivers, Chesney and Coyne 2011). These categories are not mutually exclusive (Smith et al. 2008).

\section{Bullying and mental health}

Bullying causes substantial distress and has both immediate and long-term consequences for both victim and bully (Newman, Holden and Delville 2005, Woods and White 2005, Sourander et al. 2007, Kaltiala-Heino, Fröjd and Marttunen 2010, Renda, Vassallo and Edwards 2011). Research has demonstrated relationships between bullying, decreased wellbeing, and psychopathology. Studies using cross-sectional survey data from retrospective reports of victimisation reported associations between being the victim of bullying and poorer emotional adjustment (Nansel et al. 2004), loneliness, isolation (Newman et al. 2005), psychosomatic symptoms, substance abuse (Luk, Wang and Simons-Morton 2010), trauma symptoms (Gruber and Fineran 2008), and self-harm (Hay and Meldrum 2010). In a study using quantitative survey data and qualitative data obtained through focus groups, Guerra, Williams and Sadek (2011) found the strongest predictor of an increase in victimisation to be a decrease in self-esteem. A longitudinal relationship between victimisation and increases in emotional dysregulation, depression, and suicidal ideation and attempts was also established by several studies (McLaughlin, Hatzenbuehler and Hilt 2009, Loeger et al. 2010, Turner, Finkelhor and Ormrod 2010). In a longitudinal cohort study, Sourander et al. (2007) found that a history of victimisation was a strong predictor of anxiety disorders in males. Similarly, an earlier longitudinal study by Bond et al. (2001) found that victimisation predicted the onset of anxiety and depressive symptomology in girls. A literature review by Kaltiala-Heino and Fröjd (2011) investigated the direction of causality and reported that retrospective studies among adults supported the notion that victimisation is followed by depression, while prospective follow-up studies have suggested both that victimisation from bullying may be a risk factor for depression but also that depression may impair an adolescent's social skills and self-esteem and thereby predispose adolescents to bullying (Kaltiala-Heino et al. 2010) Educationally, bullying victims have also been found to have negative perceptions of their school (Guerra et al. 2011), avoid school, have school adjustment problems (Kochenderfer and Ladd 1997), and have lower academic achievement (DeVoe et al. 2005).

Bullying behaviour also has serious implications for the bully (Woods and White 2005, Sourander et al. 2007, Renda et al. 2011). Using self-report measures bullying was reported to be associated with disruptive behaviour symptoms (Kokkinos and Panayiotou 2004) and poor peer relationships and school stress. In a mixed method study Guerra et al. (2011) found an increase in normative beliefs supporting bullying to be the strongest predictor of an increase in bullying behaviour. Furthermore, in a large two-year follow up cohort study, being a bully was found to predict later depression among boys (Kaltiala-Heino et al. 2010) and also to predict adult anti-social personality disorder (Sourander et al. 2007) and aggression (Olweus 1991, Heydenberk, Heydenberk and Tzenova 2006). This was supported by Renda et al. (2011) who, as part of a 27-year longitudinal study, investigated bullying in early adolescence and its relationship with anti-social behaviour, criminality and violence 6 and 10 years later. The study found that being a bully was a significant predictor of later anti-social behaviour and involvement with the criminal justice system, even when risk factors were accounted for. In the prospective follow-up study "From a Boy to a Man", Sourander et al. (2007) reported that rather than all victims and bullies, it was specifically victims and bullies with mental health problems who are at risk of later developing psychiatric disorders. Regardless of the direction of causality, the association between mental health difficulties and bullying offers practitioners the opportunity for prevention by intervening on both levels (KaltialaHeino and Fröjd 2011).

\section{Forgiveness and mental health}

Forgiveness, a positive psychology concept, is defined as: "(a) the reduction in vengeful and angry thoughts, feelings, and motives that may be accompanied by (b) an increase in some form of 
positive thoughts, feelings, and motives towards the offending person" Wade et al. (2014: 154). Enright, Freedman and Rique (1998) further explain that overcoming any negative feelings and judgement towards the offender is not accomplished by a person denying themselves the right to such feelings and judgement, but by trying to view the offender with compassion, kindness and love. Forgiveness is associated with a reduction in mental health problems such as social anxiety, depression, suicidal ideation, neuroticism, stress and anger (Berry and Worthington 2001, Maltby, Macaskill and Day 2001, Flanagan et al. 2012, Liu et al. 2012), and also linked with better mental health (Maltby et al. 2001), emotional well-being, health, self-esteem, conflict resolution, advice and support-seeking strategies (Flanagan et al. 2012), although it should be noted that the aforementioned studies relied on self-reported data. A study by Hui and Ho (2004) used both quantitative and qualitative methods to investigate the implementation of forgiveness in a guidance programme. Results indicated that although no significant improvement in participants' self-esteem and hope was found, participants showed a better understanding of forgiveness, had a more positive attitude towards their offenders, and were more willing to apply forgiveness as a strategy. Wade et al. (2014) conducted a meta-analysis of psychotherapeutic interventions to promote forgiveness where the methodological quality of the studies was also assessed. Interventions were found to not only reduce emotional difficulties (i.e., depression and anxiety), but enhance human functioning by providing a benefit of hope. Their results also indicated that treatment effect size was not related to the variables they used to assess methodological quality. This was confirmed by Enright et al. (2007) who found evidence that a guided forgiveness curriculum delivered by the classroom teacher, in consultation with psychologists, could lead to an increase in forgiveness and a statistically significant reduction in anger and depression. However, a limitation in this study was that randomisation was on the classroom, rather than on the child level resulting in a quasi-experimental design. Forgiveness could be viewed as an emotional juxtaposition (McCullough, Worthington and Rachal 1997, Worthington and Wade 1999), with the releasing of feelings of unforgiveness (anger, hurt, fear, vengefulness, resentment and hostility), and the introduction of more positive feelings, thoughts and behaviour towards the perpetrator, event, and yourself without necessarily forgetting, condoning or excusing the injustice (Enright 2001, Karremans and Van Lange 2004, Egan and Todorov 2009). Using a stress-and-coping framework, Worthington and Scherer (2004) explained forgiveness as an emotion-focused coping strategy that can be used to deal with the stressful and negative emotional effects of unforgiveness. Roberts (1995) offered a further distinction between forgiveness (a reaction to specific circumstances/offences) and forgivingness (an overall disposition to forgive across time, relationships and situations), while grudge-holding and a vengeful orientation have also been identified as two dispositions of unforgiveness (Mullet, Neto and Riviere 2005).

\section{Forgiveness and bullying}

Although forgiveness (and forgivingness) has received much interest in recent years, most literature has been mainly focussed on adult forgiveness (Van Dyke and Elias 2007) with a marked interest in relation to adolescent forgiveness and its relationship with bullying only occurring within the last five years. In one such study Flanagan et al. (2012) investigated forgiveness as a potential adaptive coping strategy among adolescents who were victims of bullying and found that adolescents who reported higher levels of forgiveness were likely to use conflict resolution and adviceand support-seeking strategies and less likely to endorse revenge-seeking strategies in response to bullying. In an earlier forgiveness-based intervention study with primary school pupils who experienced unforgiveness, Hui and Chau (2009) reported that, when compared to a control group, the intervention participants indicated not only a better understanding of forgiveness, but also higher levels of forgiveness, hope and self-esteem and lower levels of depression. Although this study did not focus specifically on hurt relating to being bullied, they suggested that the benefit of forgiveness could also be transferred to this setting. This was supported by Hui, Tsang and Law (2011) who advocated for the use of a developmental guidance perspective, using the positive youth development paradigm as a more proactive way of preventing bullying in schools. This approach focusses on cultivating a harmonious school environment on a whole school level through the development of interpersonal competencies and promoting values such as harmony and forgiveness. A study 
by Ahmed and Braithwaite (2005) demonstrated that perceived parental forgiveness of wrongdoing was strongly associated with reduced bullying behaviour at school, and found forgiveness to be a more effective practice than shaming. In a subsequent paper Ahmed and Braithwaite (2006) also found evidence in their mediational analysis that perceived forgiveness fostered adaptive shamemanagement skills, which in turn reduced bullying behaviour at school. Egan and Todorov (2009) posited that forgiveness could be an important coping strategy for dealing with the effects of being bullied. To date, though, little empirical testing of this concept has been undertaken. Liu et al. (2012) found evidence for forgiveness as a moderator of the association between victimisation and suicidal ideation, indicating that forgiveness could potentially offer protection against the suicidal ideation that victims of bullying may experience. However, Ramirez's (2013) qualitative study (on an admittedly small sample) did not find forgiveness as one of the coping strategies mentioned by bullied children.

Given the evidence for the relationships between bullying and mental health, forgiveness and mental health, and forgiveness and bullying, this study aims to investigate the association between these three important constructs, and the role that forgiveness might play in mediating the relationship between bullying and mental health.

\section{Method}

The study used a cross-sectional correlational design.

\section{Participants}

As the first author was employed as a psychologist for Powys Health Board, Wales, four secondary schools in the same county were approached to participate in the study. All schools were compatible as to being mainstream state schools situated in rural locations with similar anti-bullying policies. Two schools expressed an interest and agreed to take part.

\section{Measures}

The questionnaire battery did not gather any open-ended data, but utilised the Likert discussed.

The School Relationship Questionnaire (SRQ-Wolke et al. 2001) measures bullying and victimisation and was developed from the "Bullying and Friendship Patterns" child interview and adapted for use with adolescents (Woods and White 2005). The SRQ is divided into four sections: Direct Aggression Received (DAR), Verbal and Relational Aggression Received (VRAR), Direct Aggression Given (DAG) and Verbal and Relational Aggression Given (VRAG). The scores were assigned as follows: 0 indicated no occurrence, 1 indicated 'not very often (1-3 times)' 2 indicated 'often ( $\geq 4$ times)' and 3 indicated 'very often (at least once a week)'. Pupils with scores of 'often' or 'very often' in any of the subsections were classified as either a direct bully and/or victim, and/ or a relational bully and/or victim. Subscale totals, not dichotomous classification, were used for the analysis, with a higher total score indicating a more frequent occurrence of a wider variety of bullying behaviours or experiences.

The Youth Self Report scale (YSR; Achenbach and Rescorla 2001) is a widely used, reliable and valid measure of the mental health of 11-18 year olds (Ivarsson et al. 2005). The YSR provides two broad-band scales: internalising and externalising, which figure as second-order factors. The internalising dimension comprises the withdrawn/depressed, somatic complaints, and anxious/ depressed subscales. Delinquent (rule-breaking) behaviour and aggressive behaviour form the externalising dimension.

The Forgivingness Questionnaire (FQ; Mullet et al. 2003) is a self-report measure of the willingness to forgive under various circumstances and has been used with French adolescent populations (Sastre et al. 2003, Chiaramello et al. 2006). Responses are indicated on a seven-point Likert scale, varying from 'disagree completely' to 'completely agree'. Three of the four subscales of the FQ were used in this study: lasting resentment, forgiveness and revenge. The Sensitivity to Circumstances subscale was dropped, as it showed very low reliability. While high scores indicated 
a high degree of agreement with the underlying concept for each subscale, the Lasting Resentment and Revenge subscales are conceptual opposites of the Forgiveness subscale.

The Forgiveness of Self and Forgiveness of Others scale (FSFO; Mauger et al. 1992) measure Forgiveness of Self (FS) and Forgiveness of Others (FO). Participants rate whether the behaviour described is generally true or false of how they would behave. The FSFO has demonstrated a satisfactory internal reliability (Maltby et al. 2001) and an adequate test re-test reliability (Mauger et al. 1992). It was originally designed for use with an adult population therefore the items were modified slightly to make them developmentally appropriate for adolescents, and piloted in the current study. Also, to facilitate better comparison with the Forgivingness Questionnaire and thus better understanding of the eventual model, the FSFO item scores were reversed, so that high scores indicated a more forgiving attitude.

\section{Procedure}

Ethical approval for the study was obtained from the School of Psychology Ethical Committee of the University of Wales, Bangor. The design and procedure of the project was explained to the head teachers and permission was obtained for the schools to be used. As participants were under 18 years of age, consent was obtained from parents. An information sheet explaining the study and an opt-out consent form (which was only returned if parents did not want their child to take part in the study) was sent to parents via their children. No reasons were given for not consenting, and it did not appear that consent was withheld on any systematic basis. Year 10 and Year 11 pupils were informed about the study, a written outline of the study was provided and they were invited to take part by the first author. In addition, pupils were also provided with a 'Help I'm being bullied!' information sheet, listing helplines and agencies that they could contact for help. Participation was voluntary and pupils were asked to give their written consent immediately before undertaking the research. The questionnaires were completed during a Personal and Social Education (PSE) lesson and both the first author and a teacher from the school were present to assist with any questions.

\section{Analysis}

The missing data were tested for randomness, and where possible, missing values were imputed. After this, the subscales were examined for reliability (Cronbach's alpha) and construct validity (maximum likelihood factor analysis). Then structural equation models investigating the relationship between the variables were tested with LISREL.

\section{Results}

The two participating schools had a total of 639 Year 10 and Year 11 pupils. Of these, 541 obtained parental and own consent and subsequently completed the questionnaire booklet, giving a response rate of $84.66 \%$.

Data were tested and missing data were found to be Missing Completely at Random (MCAR) (Little 1988). Questionnaires with more than $10 \%$ of items missing from any particular scale were first removed, after which LISREL's (Jöreskog and Sörbom 2003) matching imputation for ordinal data was used to impute the remaining missing items (Jöreskog 2005). Any questionnaires with data which could not be imputed were removed, reducing the sample size to 355 . The final sample thus consisted of 166 (47.56\%) boys and 183 girls ( 6 not reported), with 194 and 148 from the two schools respectively (13 not reported). Their ages ranged from 14-16 years, with a median of 15 . The sample was almost entirely white $(97.5 \%)$, with $55.8 \%$ identifying themselves as Christian, $28.2 \%$ as atheist, $7.9 \%$ not answering, and $8.2 \%$ spread across other smaller religious groupings.

Table 1 shows the means and reliability coefficients of the various subscales. The univariate normality, together with the skewness and kurtosis of the subscale scores were also checked (Mardia 1970, DeCarlo 1997). Kline (1998) recommends flagging scores with kurtosis values above 10 , and skewness values outside of $|3.0|$ as being non-normal, which none of the subscales showed. 
Table 1: Means, skewness and kurtosis, and reliability of subscales

\begin{tabular}{lcrrrrc}
\hline Subscale & Skewness & Kurtosis & Mean & SD & N of items $\begin{array}{c}\text { Standardised } \\
\text { alpha }\end{array}$ \\
\hline FQ: Lasting Resentment & 0.57 & 0.06 & 14.13 & 6.48 & 5 & 0.77 \\
FQ: Forgiveness & 0.20 & -0.37 & 16.39 & 6.51 & 3 & 0.73 \\
FQ: Revenge & 0.31 & -0.71 & 10.55 & 4.91 & 5 & 0.74 \\
FSFO: Others & -0.06 & -0.55 & 8.62 & 2.69 & 15 & 0.55 \\
FSFO: Self & 0.07 & -0.72 & 7.45 & 3.24 & 15 & 0.71 \\
YSR: Internalising & 1.17 & 1.52 & 12.77 & 9.28 & 31 & 0.91 \\
YSR: Anxious/depressed & 1.11 & 1.18 & 5.46 & 4.36 & 13 & 0.84 \\
YSR: Withdrawn/depressed & 1.13 & 1.13 & 3.23 & 2.66 & 8 & 0.71 \\
YSR: Somatic complaints & 1.23 & 1.93 & 4.09 & 3.54 & 10 & 0.80 \\
YSR: Externalising & 1.06 & 0.85 & 15.21 & 10.17 & 32 & 0.92 \\
YSR: Delinquent behaviour & 1.21 & 1.57 & 6.77 & 5.02 & 15 & 0.85 \\
YSR: Aggressive behaviour & 0.93 & 0.38 & 8.44 & 5.87 & 17 & 0.87 \\
SRQ: Direct Aggression Given & 2.27 & 5.58 & 0.64 & 1.14 & 4 & 0.53 \\
SRQ: Direct Aggression Received & 1.83 & 3.19 & 1.04 & 1.57 & 4 & 0.63 \\
SRQ: Verbal/Relational Aggression Given & 1.49 & 2.35 & 1.2 & 1.44 & 5 & 0.46 \\
SRQ: Verbal/Relational Aggression Received & 1.50 & 2.46 & 2.31 & 2.54 & 5 & 0.76
\end{tabular}

Table 2 shows the inter-correlations between the various subscales. All of the inter-correlations were significant at either the $5 \%$ or, more commonly, the $1 \%$ level. Nonetheless in terms of effect size, most of the correlations were weak to moderate. Of greatest concern, in terms of multicollinearity, was the correlation between SRQ-VRAR and SRQ-DAR, although this correlation would be quite understandable, as it merely indicated that direct and verbal aggression went hand in hand.

\section{Prevalence of bullying and mental health}

The prevalence of bullying within the sample was $6.8 \%$ for direct bully, $13.5 \%$ for direct victim, $2.3 \%$ for direct bully/victim, $16.3 \%$ for relational bully, $33.8 \%$ for relational victim and $9.6 \%$ for relational bully/victim, which was similar to that of another UK study using the same bullying measure (Woods and White 2005). However, one noteworthy difference to that study was the considerably lower prevalence of relational bully/victims in our sample. In both studies relational victims were the most prevalent.

While raw scores were used for later analyses, normalised scores were used to assess the prevalence of mental health problems - as is recommended by Achenbach and Rescorla (2001). The sample in this study showed prevalence rates (Table 3) similar to the norm sample (Achenbach and Rescorla 2001). In relation to gender, girls were found to score consistently higher in both the internalising and externalising dimensions, corroborating the findings of Ivarsson et al. (2005).

\section{Prevalence of forgiveness}

The forgiveness measures did not have standardised cut-off scores, making it impossible to establish prevalence. Within this sample the means for the FSFO subscales (on a scale from 0-15) were: F O: 8.62, F S: 7.45. The means for the FQ subscales were: lasting resentment: 14.13 and revenge: 10.55 (both scaled from 5-35), and forgiveness: 16.39 (scaled from 3-21).

\section{Relationship between mental health, forgiveness and bullying and victimisation}

Next, a model of the relationship between bullying, being victimised, internalising and externalising pathologies, and forgiveness was constructed. LISREL 8.5 (Jöreskog and Sörbom 2003) was used to test a structural equation model reflecting the influence of forgiveness as a mediator of the impact of bullying and victimisation on psychopathology. To evaluate the fit of the models, the following fit indices were selected: The root mean square error of approximation (RMSEA; Steiger and Lind 1980, Steiger 1990, Browne and Cudeck 1992, MacCallum, Browne and Sugawara 1996, 
Table 2: Intercorrelations between subscales $(N=355)$

\begin{tabular}{|c|c|c|c|c|c|c|c|c|c|c|c|c|c|c|c|}
\hline Scale & $\mathrm{FQ}$ & & FSFO & & SRQ & & & & YSR & & & & & & \\
\hline Subscale & $\mathrm{F}$ & $\mathrm{R}$ & $\mathrm{FO}$ & FS & DAG & DAR & VRAG & VRAR & AD & WD & SC & DB & $A B$ & $\mathrm{I}$ & $E$ \\
\hline Lasting Resentment (LR) & $-0.37^{* *}$ & $0.49^{* *}$ & $-0.40^{* *}$ & $-0.20^{* *}$ & $0.18^{* *}$ & $0.20^{\star *}$ & $0.19^{* *}$ & $0.21^{* *}$ & $0.22^{* *}$ & $0.25^{* *}$ & $0.24^{\star *}$ & $0.39^{\star *}$ & $0.43^{* *}$ & $0.27^{* *}$ & $0.44^{* *}$ \\
\hline Forgiveness $(F)$ & & $-0.46^{\star *}$ & $0.29^{* *}$ & $-0.12^{*}$ & $-0.11^{*}$ & -0.03 & -0.07 & -0.03 & 0.05 & 0.04 & -0.05 & $-0.25^{\star \star}$ & $-0.23^{\star *}$ & 0.02 & $-0.26^{\star *}$ \\
\hline Revenge (R) & & & $-0.54^{\star *}$ & -0.07 & $0.29^{\star *}$ & $0.14^{\star *}$ & $0.24^{\star \star}$ & 0.10 & 0.08 & $0.16^{* *}$ & $0.16^{\star *}$ & $0.47^{* *}$ & $0.45^{\star *}$ & $0.15^{\star \star}$ & $0.49^{\star *}$ \\
\hline Forgiveness of Others (FO) & & & & $0.28^{* *}$ & $-0.24^{\star *}$ & $-0.13^{*}$ & $-0.29^{\star *}$ & $-0.18^{\star *}$ & $-0.16^{* *}$ & $-0.13^{*}$ & $-0.18^{* *}$ & $-0.45^{\star \star}$ & $-0.47^{* *}$ & $-0.18^{\star *}$ & $-0.50^{\star *}$ \\
\hline Forgiveness of Self (FS) & & & & & $-0.12^{*}$ & $-0.25^{\star *}$ & $-0.11^{*}$ & $-0.30^{* *}$ & $-0.52^{\star *}$ & $-0.38^{* *}$ & $-0.33^{* *}$ & $-0.19^{\star *}$ & $-0.25^{\star *}$ & $-0.48^{* *}$ & $-0.24^{* *}$ \\
\hline $\begin{array}{l}\text { Direct Aggression Given } \\
\text { (DAG) }\end{array}$ & & & & & & $0.34^{* *}$ & $0.52^{* *}$ & $0.25^{\star *}$ & $0.21^{* *}$ & $0.19^{* *}$ & $0.15^{* *}$ & $0.37^{* *}$ & $0.41^{* *}$ & $0.21^{* *}$ & $0.42^{* *}$ \\
\hline $\begin{array}{l}\text { Direct Aggression Received } \\
\text { (DAR) }\end{array}$ & & & & & & & $0.29^{\star *}$ & $0.70^{* *}$ & $0.51^{* *}$ & $0.35^{\star *}$ & $0.40^{* *}$ & $0.23^{* *}$ & $0.28^{* *}$ & $0.49^{* *}$ & $0.28^{* *}$ \\
\hline $\begin{array}{l}\text { Verbal/Relational } \\
\text { Aggression Given (VRAG) }\end{array}$ & & & & & & & & $0.36^{* *}$ & $0.23^{* *}$ & $0.22^{\star *}$ & $0.25^{\star *}$ & $0.45^{\star *}$ & $0.45^{\star *}$ & $0.27^{\star *}$ & $0.48^{* *}$ \\
\hline $\begin{array}{l}\text { Verbal/Relational Aggression } \\
\text { Received (VRAR) }\end{array}$ & & & & & & & & & $0.53^{* *}$ & $0.39^{\star *}$ & $0.42^{\star *}$ & $0.24^{* *}$ & $0.33^{* *}$ & $0.52^{\star *}$ & $0.31^{* *}$ \\
\hline Anxious/depressed (AD) & & & & & & & & & & & & & & & \\
\hline Withdrawn/depressed (WD) & & & & & & & & & & & & & & & \\
\hline Somatic complaints (SC) & & & & & & & & & & & & & & & \\
\hline Delinquent behaviour (DB) & & & & & & & & & & & & & & & \\
\hline Aggressive behaviour (AB) & & & & & & & & & & & & & & & \\
\hline Internalising (I) & & & & & & & & & & & & & & & \\
\hline Externalising $(\mathrm{E})$ & & & & & & & & & & & & & & & \\
\hline
\end{tabular}


Table 3: Proportion of YSR Clinically significant scores

\begin{tabular}{lcccc}
\hline \multirow{2}{*}{ Gender } & \multicolumn{2}{c}{ Internalising } & \multicolumn{2}{c}{ Externalising } \\
\cline { 2 - 5 } & Borderline $(\mathrm{T}=60-63)$ & Clinical $(\mathrm{T} \geq 64)$ & Borderline $(\mathrm{T}=60-63)$ & Clinical $(\mathrm{T} \geq 64)$ \\
\hline Male & $5.4 \%$ & $6.6 \%$ & $7.2 \%$ & $9.0 \%$ \\
Female & $6.6 \%$ & $12.0 \%$ & $7.1 \%$ & $12.0 \%$
\end{tabular}

Nevitt and Hancock 2000, Steiger 2000), where values smaller than 0.08 would indicate a fair model fit, with smaller values indicating better fit. The Goodness of Fit Index (GFI; Marsh, Balla and McDonald 1988, Mulaik et al. 1989), with values greater than 0.9 indicating good model fit. The Comparative Fit Index (CFI; Bentler 1990, Hu and Bentler 1995, West, Finch and Curran 1995, Fan and Wang 1998), with values closer to 1 indicating better fit.

The first task was to construct a suitable measurement model. Because of the sheer number of items, subscale totals were used as manifest variables, instead of individual item responses, also circumventing some of the problems associated with the analysis of ordinal data. For the YSR, the second-order factors (internalising and externalising) provided the needed latent factors and their constituent subscales were used as manifest variables. Table 2 shows that, as expected, the YSR subscales correlated strongly with the factors of which they were members. The various SRQ subscales also readily yielded two factors: bully and victim, each with two measurements: direct and verbal/relational aggression given for bully and direct and verbal/relational aggression received for victim. The respective SRQ subscales correlated much stronger with their factor-partner than with the two subscales from the other factor, indicating an acceptable degree of convergent and discriminant construct validity (Table 2).

The only slightly problematic construct was forgiveness (and forgivingness). Two scales (the FQ and the FSFO) were used, with three- and two subscales respectively. Of the five subscales, four showed high inter-correlations all around (lasting resentment, forgiveness, revenge and forgiving others), albeit in opposing directions. Upon examination of the item content, they were grouped as a single FO factor. The remaining subscale was then taken as FS, as intended in the FSFO. For the model to be identified, each latent variable was scaled against one of its manifest variables (arbitrarily chosen) and the error variance of the FS factor was set to zero, fully equating it with its single underlying manifest measurement. A basic measurement model allowing all latent variables to covary showed good fit $($ RMSEA $=0.066)$. The various standardised loadings of the manifest variables are shown in the final model. The standardised inter-correlations between the latent variables (LISREL's $\phi$ matrix) are shown in Table 4.

Looking at both the literature concerning the various concepts, and the inter-correlations between the various subscales (Table 2), it was decided to test two separate mediation pathways. The first would test whether forgiving others would mediate the effect of being a bully on externalising psychopathology. The second would reflect a similar 'internal' structure: whether forgiving oneself would mediate the effect of being a victim of bullying behaviour on internalising psychopathology. The advantage to this approach, above a regression analysis, is that with the latter, two analyses would have to be performed, one for each dependant variable (and thus in isolation), whereas with a structural model, the two can be analysed concurrently, providing a better reflection

Table 4: Intercorrelations among latent variables

\begin{tabular}{lccccc}
\hline & $\begin{array}{c}\text { Internal } \\
\text { psychopathology }\end{array}$ & $\begin{array}{c}\text { External } \\
\text { psychopathology }\end{array}$ & Bully & Victim & $\begin{array}{c}\text { Forgiving } \\
\text { others }\end{array}$ \\
\hline External Psychopathology & 0.60 & & & & \\
Bully & 0.37 & 0.67 & & & \\
Victim & 0.67 & 0.39 & 0.52 & & \\
Forgiving Others & 0.24 & 0.70 & 0.45 & 0.24 & \\
Forgiving Self & -0.52 & -0.26 & -0.15 & -0.33 & -0.18
\end{tabular}


Table 5: Path estimates and fit indices for various models tested

\begin{tabular}{|c|c|c|c|c|c|c|c|}
\hline Path estimates & Model 1 & Model 2 & Model 3 & Model 4 & Model 5 & Model 6 & $\begin{array}{c}\text { Model } 7 \\
\text { (Full model) }\end{array}$ \\
\hline Bully->Forgiving Others & 0.69 & & & 0.68 & & 0.57 & 0.45 \\
\hline Bully->Externalising & & 0.87 & & 0.88 & 0.47 & & 0.48 \\
\hline $\begin{array}{l}\text { Forgiving Others-> } \\
\text { Externalising }\end{array}$ & & & 0.78 & & 0.50 & 0.77 & 0.48 \\
\hline Victim->Forgiving Self & -0.39 & & & -0.42 & & -0.34 & -0.34 \\
\hline Victim->Internalising & & 0.75 & & 0.74 & 0.57 & & 0.57 \\
\hline $\begin{array}{l}\text { Forgiving Self-> } \\
\text { Internalising }\end{array}$ & & & -0.53 & & -0.34 & -0.53 & -0.34 \\
\hline \multicolumn{8}{|l|}{ Model fit indices } \\
\hline$\chi^{2}$ & 288.2 & 348.71 & 417.19 & 358.46 & 260.06 & 424.46 & 264.54 \\
\hline Df & 70 & 70 & 70 & 73 & 68 & 73 & 71 \\
\hline RMSEA & 0.083 & 0.096 & 0.102 & 0.096 & 0.078 & 0.099 & 0.076 \\
\hline GFI & 0.90 & 0.87 & 0.86 & 0.87 & 0.91 & 0.86 & 0.91 \\
\hline CFI & 0.94 & 0.92 & 0.91 & 0.92 & 0.95 & 0.90 & 0.95 \\
\hline
\end{tabular}

of the interdependent nature of the variables. Structural models also provide better assessment of mediation than regression models (lacobucci, Saldanha and Deng 2007).

Although one of the advantages to testing mediation with structural models is that only the full model needs testing (lacobucci et al. 2007) a clearer picture of the effect of the introduction of the mediating variable is formed when the path coefficients with and without it are compared. Table 5 shows the path estimates for the various models tested. For Models 1-3, each 'similar' path from each loop was tested individually and the others constrained. Models 4-6 show the various combinations of two paths from each loop. Model 7 shows the full mediation loop (this is the actual model tested and will be the focus of the further discussion). Model 1 showed a strong positive relationship between bullying and an unwillingness to forgive others, and a strong negative relationship between being a victim and the willingness to forgive oneself. Both being a bully and being a victim show strong relationships (Model 2) to internalising and externalising psychopathology respectively. Furthermore, not forgiving others is very strongly correlated with externalising psychopathology, while

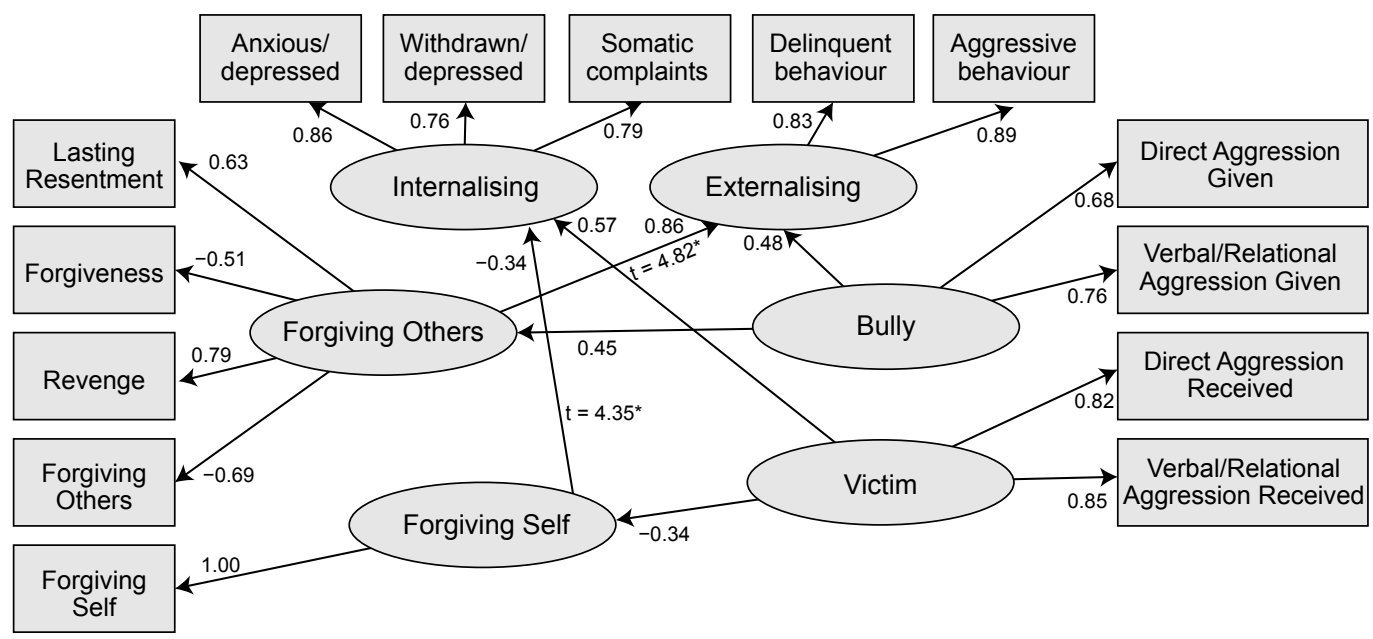

Figure 1: Mediation Model 
forgiving oneself is strongly correlated with a reduction in internalising psychopathology (Model 3). Models 4-6 show that the effects of being a bully or being bullied are weakened when not forgiving others or forgiving self is introduced. However, Model 7 is the model in which the full mediation loops are closed, and this model shows the best fit (RMSEA $=0.076)$, and also shows the largest reductions in the effect of bullying on externalising psychopathology and being bullied on internalising psychopathology respectively. The full model is shown in Figure 1.

The $t$-values supplied by LISREL for both mediating loops were statistically significant. Also, the mediating effect can be estimated as the ratio of the indirect effect to the total effect as reported in LISREL (lacobucci et al. 2007): 31.2\% for bully->forgiving others->external and $16.7 \%$ for victim$>$ forgiving self->internal. The z-tests (Sobel 1982, Baron and Kenny 1986, MacKinnon, Lockwood and Williams 2004) for the mediating effect of both loops were both significant ( $z=3.96$ for bully$>$ forgiving others->external; $z=-5.95$ for victim->forgiving self->internal), confirming the mediation effects in both. When one examines the change in the effect of bullying on externalising psychopathology (Table 5 and Figure 1), it becomes clear that FO has a significant mediating effect-the strength of the relationship drops from 0.87 to 0.48 . The same effect can be seen when examining the relationship between victimisation and internalising psychopathology. When tested alone, the path shows a coefficient of 0.75 , which drops to 0.57 when the mediating path of FS is introduced.

A careful consideration of the various path coefficients will help explain what the model reveals. Forgiving others as a latent construct shows negative loadings for the forgiveness and forgiving others manifest variables, and positive loadings for the lasting resentment and revenge variables. This means that as the construct is defined in the model, high scores for the construct indicate an unforgiving attitude. This explains the positive correlation between the bullying and forgiving others constructs, as well as between forgiving others and externalising psychopathology. This must always be borne in mind, since the model merely reflects the mathematical relationships between the variables, and the signs could easily be reversed, or the factor renamed to 'not forgiving others'. In contrast to the (not) forgiving others construct, the forgiving self-construct is fully defined by its underlying manifest variable, and thus a high score here indicates a strong tendency to forgive oneself. This particular mediating loop is interesting. Firstly, as one would expect, being the victim of bullying behaviour shows a strong positive relationship with internalising psychopathology. Also of great interest is that being able to forgive oneself shows a strong negative relationship with internalising psychopathology. But what is surprising is the mediating effect of forgiving oneself on the relationship between being victimised and internalising psychopathology. Consider first that being victimised shows a negative relationship with forgiving oneself. This means that victims of bullying find it harder to forgive themselves or, stated differently, that victims of bullying tend to blame themselves. However, for those who do forgive themselves, the possible outcome of internalising psychopathology in response to being victimised is reduced-a significant finding.

\section{Discussion}

This study explored the impact of bullying on mental health and the mediating influence of forgiveness. The prevalence rates of bullying and victimisation, and of internalising and externalising psychopathology were similar to previously reported findings (Achenbach and Rescorla 2001, Woods and White 2005). This study found a relationship between bullying, mental health and forgiveness. The model shows strong relationships between bullying behaviour and both externalising psychopathology, and the tendency to not forgive others. Adolescents who reported higher levels of bullying and victimisation were more likely to report greater mental health problems. Bullies reported higher levels of aggressive and delinquent behaviour (externalising psychopathology). Of perhaps greater interest is the fact that not being willing to forgive others is strongly associated with externalising psychopathology. Victims had a strong association with depression, anxiety, somatic complaints and withdrawal (internalising psychopathology). Furthermore, the results of this study suggest that adolescents who indicated less difficulty with forgiveness reported lower levels of mental health problems. This is in accordance with the previous findings (Hui and Chau 2009, Flanagan et al. 2012, Liu et al. 2012). 
This study clearly shows that an inability to engage in forgiveness of self was related to higher levels of internalising difficulties, while an inability to forgive others was more closely related to higher externalising difficulties. This finding makes intuitive sense when considered within the context of attribution theory (Kelley 1967). For individuals at risk of internalising problems resulting from victimisation, engaging in forgiveness of self should lead to the establishment of internal attributions which could have an impact on the complex cognitions that influence the development of anxiety and depression, such as worthlessness and helplessness (Beck 1976). For externalising problems, forgiveness should lead to the establishment of external attributions about the intentions of others, reducing negative reactions to other people's behaviour, and therefore potentially reducing externalising behaviour.

This study found evidence for the mediating effect of forgiveness on the impact of bullying and victimisation on psychopathology. That bullying behaviour would be associated with externalising psychopathology is neither a new, nor an unexpected finding (Kokkinos and Panayiotou 2004, Heydenberk et al. 2006). However, that being able to forgive others would be associated with less bullying, and with lower levels of externalising psychopathology is significant. Similarly, the association between being victimised and showing internalising psychopathology is not surprising (Newman et al. 2005, Luk et al. 2010, Liu et al. 2012). But finding that forgiving oneself reduces the impact of victimisation on internalising psychopathology is important. The results of this study, then, suggest that adolescents who experience bullying and victimisation and report being able to forgive will be more likely to report lower levels of mental health difficulties.

The facilitative role of forgiveness in mediating the relationship between bullying and forgiveness can be understood from a coping perspective. Egan and Todorov (2009) discussed the theoretical link between bullying and forgiveness. They highlighted that adolescents in school have less control over their environment than adults, and when bullied are less able to use problem-focused coping solutions such as leaving school. Therefore the utility of forgiveness is that it provides a useful emotion-focused coping solution for individuals in schools who have little influence over their circumstances or environment. This was also supported by the findings of Flanagan et al. (2012). The results of our study add to the findings by Ahmed and Braithwaite (2006) who reported evidence for a mediational link between forgiveness and bullying via shame management. However, as far as the authors are aware, forgiveness as a mediator between bullying and victimisation and mental health problems has not, until now, been investigated.

\section{Limitations}

This study had some limitations that should be considered in the interpretation of the results. First, the data are based on pupils' self-report, and recall bias may result in over- or under-reporting. Future studies should consider a multi-informant approach to confirm that responses are reliable. Second, participants were recruited from rural, predominantly white schools, limiting the generalisability of the results. It is recognised that this research has been conducted within one culture, life-stage and geographic area, while variations in the relationship between bullying and victimisation, mental health difficulties and forgiveness, might be found between cultures, areas (rural vs. urban) or different contexts (for example, between schools that vary with respect to anti-bullying or pupil support policies). Future studies should attempt to replicate the results in more ethnically diverse populations in, for example, an urban area. Third, the study did not examine fully bullies who are also bullied themselves (bully/victims). These individuals show the greatest psychopathology and pose most risk of adverse long-term outcomes (Sourander et al. 2007). This underscores the need for further research in relation to forgiveness as a mediating factor for the mental health problems experienced by this particular subgroup, especially, for them, forgiveness of others. Fourth, the study was cross-sectional which precludes the possibility of examining issues of causality. Longitudinal studies, measuring individual differences before and after bullying are needed. Future investigation into the area of causality is warranted, although establishing that these problems coexist is also important (Mills et al. 2004). Fifth, the reduction in the sample size used for the modelling due to missing data was unfortunate. However, the data was tested and shown to be MCAR, and the rigour of using only complete data was preferred to using a larger sample. Lastly, 
sampling a small number of bullies and victims for in-depth interviews could have provided a richer understanding into the data, but was beyond the scope of this study.

\section{Conclusion}

Coggan et al. (2003) found that for adolescents to achieve in social, academic and physical settings, positive mental health is a precondition. Their study emphasised the "need for mental health promotion, positive youth development, prevention and early intervention strategies to eliminate bullying in schools settings. There is a need to shift collective thinking towards a more positive, strength-based approach" ( $p$ 21). Forgiveness can be seen as a key element in addressing the limitations of traditional anti-bullying measures and helping the victims of bullying overcome the emotional damage caused by this prevalent problem (Egan and Todorov 2009). This is supported by findings from this study that highlight the role of forgiveness as an additional element to such an approach, suggesting that forgiveness could be a valuable topic to include in anti-bullying programmes. Egan and Todorov (2009) conclude that as bullying is seen as an interpersonal offence and forgiveness facilitates coping with such transgressions, the combination of school bullying and forgiveness is logical. Furthermore, on a clinical level this study emphasises the importance of paying particular attention to self-forgiveness when working therapeutically with victims of bullying and the internalising psychopathology that they may present with. While, when working with bullies, learning to forgive others might help to reduce their aggressiveness and other conduct problems. The importance of this study is not only in that it shows that being a bully is related to externalising psychopathology, nor that being bullied is related to internalising psychopathology, but that it suggests that forgiveness can, to an extent, mitigate the impact of these life experiences on the eventual outcome of psychopathology. This indicates that forgiveness can be valuable as part of educational anti-bullying programmes and within clinical settings, and emphasises the role of positive psychology and more specifically forgiveness in a variety of applications.

Acknowledgements - We thank the NWCPP, School of Psychology, University of Bangor and Dr Dave Daley who were involved in this research project and ensured its success.

\section{References}

Achenbach TM, Rescorla LA. 2001. Manual for the ASEBA School-Age Forms and Profiles. Burlington, Vermont: Research Centre for Children, Youth, and Families.

Ahmed E, Braithwaite V. 2004. Bullying and victimization: cause for concern for both families and schools. Social Psychology of Education 7: 35-54.

Ahmed E, Braithwaite V. 2005. Forgiveness, shaming, shame and bullying. The Australian and New Zealand Journal of Criminology 38: 298-323.

Ahmed E, Braithwaite V. 2006. Forgiveness, reconciliation, and shame: Three key variables in reducing school bullying. Journal of Social Issues 62: 347-370.

Baron RM, Kenny DA. 1986. The moderator-mediator variable distinction in social psychological research: Conceptual, strategic, and statistical considerations. Journal of Personality and Social Psychology 51: 1173-1182.

Beck AT. 1976. Cognitive therapy and the emotional disorders. New York: International University Press.

Bentler PM. 1990. Comparative fit indexes in structural models. Psychological Bulletin 107: 238-246.

Berry JW, Worthington EL. 2001. Forgiveness, relationship quality, stress while imagining relationship events, and physical and mental health. Journal of Counselling Psychology 48: 447-455.

Bond L, Carlin JB, Thomas L, Rubin K, Patton G. 2001. Does bullying cause emotional problems? A prospective study of young teenagers. British Medical Journal 323: 480-484.

Browne MW, Cudeck R. 1992. Alternative ways of assessing model fit. Sociological Methods and Research 21: 230-258.

Chiaramello S, Mesnil M, Sastre MTM, Mullet E. 2006. Dispositional forgiveness among adolescents. Unpublished Manuscript. 
Coggan C, Bennett S, Hooper R, Dickinson P. 2003. Association between bullying and mental health status in New Zealand adolescents. International Journal of Mental Health Promotion 5: 16-22.

DeCarlo LT. 1997. On the meaning and use of kurtosis. Psychological Methods 2: 292-307.

DeVoe E, Dean K, Traube D, McKay M. 2005. The SURVIVE community project: A family-based intervention to reduce the impact of violence exposures in urban youth. Journal of Aggression, Maltreatment and Trauma 11: $95-116$.

Egan LA, Todorov N. 2009. Forgiveness as a coping strategy to allow school students to deal with the effects of being bullied: Theoretical and empirical discussion. Journal of Social and Clinical Psychology 28: $198-222$.

Enright RD. 2001. Forgiveness is a choice. Washington, DC: APA LifeTools, American Psychological Association.

Enright RD, Freedman SR, Rique J. 1998. The psychology of interpersonal forgiveness. In: Enright RD, North J (eds), Exploring forgiveness. Madison: The University of Wisconsin Press. pp 46-62.

Enright RD, Knutson Enright JA, Holter AC, Baskin T, Knutson C. 2007. Waging peace through forgiveness in Belfast, Northern Ireland II: Educational programs for mental health improvement of children. Journal of Research in Education 17: 63-78.

Fan X, Wang L. 1998. Effects of potential confounding factors on fit indices and parameter estimates for true and misspecified SEM models. Educational and Psychological Measurement 58: 701-735.

Flanagan KS, Vanden Hoek KK, Ranter JM, Reich HA. 2012. The potential of forgiveness as a response for coping with negative peer experiences. Journal of Adolescence 35: 1215-1223.

Gruber JE, Fineran S. 2008. Comparing the impact of bullying and sexual harassment victimization on the mental and physical health of adolescents. Sex Roles 59: 1-13.

Guerra NG, Williams KR, Sadek, S. 2011. Understanding bullying and victimization during childhood and adolescence: a mixed methods study. Child Development 82: 295-310.

Hay C, Meldrum R. 2010. Bullying victimization and adolescent self-harm: Testing hypotheses from general strain theory. Journal of Youth Adolescence 39: 446-459.

Heydenberk RA, Heydenberk WR, Tzenova V. 2006. Conflict resolution and bully prevention: Skills for school success. Conflict Resolution Quarterly 24: 55-69.

Hu L, Bentler P M. 1995. Evaluating model fit. In: Hoyle RH (ed.), Structural equation modeling: Concepts, issues and applications. Newbury Park: Sage. pp 76-99.

Hui EKP, Chau TS. 2009. The impact of a forgiveness intervention with Hong Kong Chinese children hurt in interpersonal relationships. British Journal of Guidance and Counselling 37: 141-156.

Hui EKP, Ho DKY. 2004. Forgiveness in the context of developmental guidance: implementation and evaluation. British Journal of Guidance and Counselling 32: 477-492.

Hui EKP, Tsang SKM, Law BCM. 2011. Combating school bullying through developmental guidance for positive youth development and promoting harmonious school culture. The Scientific World Journal 11: 2266-2277.

lacobucci D, Saldanha N, Deng X. 2007. A meditation on mediation: Evidence that structural equations models perform better than regressions. Journal of Consumer Psychology 17: 140-154.

Ivarsson T, Broberg AG, Arvidsson T, Gillberg C. 2005. Bullying in adolescence: Psychiatric problems in victims and bullies as measured by the Youth Self Report (YSR) and the Depression Self-Rating Scale (DSRS). Nordic Journal of Psychiatry 59: 365-373.

Jöreskog KG. 2005. Structural equation modeling with ordinal variables using LISREL. Technical report, Scientific Software International, Inc., Lincolnwood, IL. Available at http://www.ssicentral.com/lisrel/techdocs/ ordinal.pdf [INSERT DATE ACCESSED].

Jöreskog KG, Sörbom D. 2003. LISREL 8.54 for Windows [Computer software]. Skokie, II: Scientific Software International, Inc.

Kaltiala-Heino R, Fröjd S, Marttunen M. 2010, Involvement in bullying and depression in a 2-year follow-up in middle adolescence. European Child and Adolescent Psychiatry 19: 45-55.

Kaltiala-Heino R, Fröjd S. 2011. Correlation between bullying and clinical depression in adolescent patients. Adolescent Health, Medicine and Therapeutics 2: 37-44.

Karremans JC, Van Lange PAM. 2004. Back to caring after being hurt: The role of forgiveness. European Journal of Social Psychology 34: 207-227.

Kelley HH. 1967. Attribution theory in social psychology. Nebraska Symposium on Motivation 15: $192-238$.

Kim YS, Leventhal BL, Koh YJ, Hubbard A, Boyce WT. 2006. School bullying and youth violence: causes or consequences of psychopathologic behavior? Archives of General Psychiatry 63: 1035-41.

Kline RB. 1998. Principles and practice of structural equation modeling. New York: Guilford.

Kochenderfer BJ, Ladd GW. 1997. Victimized children's responses to peers' aggression: Behaviors associated with reduced versus continued victimization. Development and Psychopathology 9: 59-73. 
Kokkinos CM, Panayiotou G. 2004. Predicting bullying and victimization among early adolescents: Associations with Disruptive Behavior Disorders. Aggressive Behavior 30: 520-533.

Little, RJA. 1988. A test of missing completely at random for multivariate data with missing values. Journal of the American Statistical Association 83: 1198-1202.

Liu X, Lu D, Zhou L, Su L. 2012. Forgiveness as a moderator of the association between victimization and suicidal ideation. Indian Paediatrics 5: 1-9.

Loeger L, Allison S, Korossy-Horwood R, Eckert KA, Goldney RD. 2010. Is a history of school bullying victimization associated with adult suicidal ideation? A South Australian population-based observational study. The Journal of Nervous and Mental Disease 198: 728-733.

Luk JW, Wang J, Simons-Morton BG. 2010. Bullying victimization and substance use among U.S. adolescents: Mediation by depression. Prevention Science 11: 355-359.

MacCallum RC, Browne MW, Sugawara HM. 1996. Power analysis and determination of sample size for covariance structure modeling. Psychological Methods 1: 130-149.

MacKinnon SP, Lockwood CM, Williams J. 2004. Confidence limits for the indirect effect: Distribution of the product and resampling methods. Multivariate Behavioral Research 39: 99-128.

Maltby J, Macaskill A, Day L. 2001. Failure to forgive self and others: a replication and extension of the relationship between forgiveness, personality, social desirability and general health. Personality and Individual Differences 30: 881-885.

Mardia KV. 1970. Measurement of multivariate skewness and kurtosis with applications. Biometrika 57: 519-530.

Marsh HW, Balla JR, McDonald RP. 1988. Goodness-of-fit indices in confirmatory factor analysis: The effect of sample size. Psychological Bulletin 103(3): 391-410.

Mauger PA, Perry JE, Freeman T, Grove DC, McBride AG, McKinney KE. 1992. The measurement of forgiveness: Preliminary Research. Journal of Psychology and Christianity 11: 170-180.

McCullough ME, Worthington EL, Rachal KC. 1997. Interpersonal forgiving in close relationships. Journal of Personality and Social Psychology 73: 321-336.

McLaughlin KA, Hatzenbuehler ML, Hilt LM. 2009. Emotional dysregulation as a mechanism linking peer victimization to internalizing symptoms in adolescents. Journal of Consulting and Clinical Psychology 77: 894-904.

Mills C, Guerin S, Lynch F, Daly I, Fitzpatrick C. 2004. The relationship between bullying, depression and suicidal thoughts/behaviour in Irish adolescents. Irish Journal of Psychiatric Medicine 21: 112-116.

Monks CP, Coyne I. 2011. A history of research into bullying. In: Monks CP, Coyne I (eds), Bullying in different contexts. New York: Cambridge University Press. pp 1-11.

Mulaik SA, James LR, Van Alstine J, Bennett N, Lind S, Stilwell CD. 1989. Evaluation of goodness-of-fit indices for structural equation models. Psychological Bulletin 105: 430-445.

Mullet E, Barros J, Frongia L, Usaï V, Neto F, Shafighi SR. 2003. Religious involvement and the forgiving personality. Journal of Personality 71: 1-19.

Mullet E, Neto F, Riviere S. 2005. Personality and its effects on resentment, revenge, and forgiveness and on self-forgiveness. In: Worthington EL (ed), Handbook of forgiveness. New York: Brunner-Routledge. pp159-182.

Nansel T, Craig W, Overpeck M, Saluja G, Ruan J, Health Behaviour in School-aged Children Bullying Analyses Working Group. 2004. Cross-national consistency in the relationship between bullying behaviours and psychosocial adjustment. Archives of Pediatrics and Adolescent Medicine 158: 730-736.

Nevitt J, Hancock GR. 2000. Improving the root mean square error of approximation for nonnormal conditions in structural equation modeling. Journal of Experimental Education 68: 251-268.

Newman ML, Holden GW, Delville Y. 2005. Isolation and the stress of being bullied. Journal of Adolescence 28: 343-357.

Olweus D. 1991. Bully/victim problems among schoolchildren: basic facts and effects of a school based intervention program. In: Pepler D, Rubin K (eds), The development and treatment of childhood aggression. Hillsdale, New Jersey: Erbaum. pp 411-448.

Ramirez O. 2013. Survivors of school bullying: A collective case study. Children and Schools 35: 93-99, doi: $10.1093 / \mathrm{cs} / \mathrm{cdt} 001$.

Renda J, Vassallo S, Edwards B. 2011. Bullying in early adolescence and its association with anti-social behaviour, criminality and violence 6 and 10 years later. Criminal Behaviour and Mental Health 21: 117-127.

Rivers I, Chesney T, Coyne I. 2011. Cyberbullying. In: Monks CP, Coyne I (eds), Bullying in different contexts. New York: Cambridge University Press. pp 211-230.

Roberts RC. 1995. Forgivingness. American Philosophical Quarterly 32: 289-306. 
Sastre MTM, Vinsonneau G, Neto F, Girard M, Mullet E. 2003. Forgivingness and satisfaction with life. Journal of Happiness Studies 4: 323-335.

Smith PK. 2011. Bullying in schools: thirty years of research. In: Monks CP, Coyne I (eds), Bullying in different contexts. New York: Cambridge University Press. pp 36-59.

Smith PK, Mahdavi J, Carvalho M, Fisher S, Russell S, Tippett N. 2008. Cyberbullying: its nature and impact in secondary school pupils. Journal of Child Psychology and Psychiatry 49: 378-385.

Sobel ME. 1982. Asymptotic confidence intervals for indirect effects in structural equation models. Sociological Methodology 13: 290-312.

Sourander A, Jensen P, Rönning JA, Niemelä S, Helenious H, Sillanmäki L, Almqvist F. 2007. What is the early adulthood outcome of boys who bully or are bullied in Childhood? The Finnish "From a Boy to a Man" Study. Pediatrics 120: 397-404.

Steiger JH. 1990. Structural model evaluation and modification: An interval estimation approach. Multivariate Behavioral Research 25: 173-180.

Steiger JH. 2000. Point estimation, hypothesis testing, and interval estimation using the RMSEA: Some comments and a reply to Hayduk and Glaser. Structural Equation Modelling 7: 149-162.

Steiger JH, Lind JC. 1980. Statistically-based tests for the number of common factors. Paper presented at the annual meeting of the Psychometric Society, lowa City, lowa.

Turner HA, Finkelhor D, Ormrod R. 2010. The effects of adolescent victimization on self-concept and depressive symptoms. Child Maltreatment 15: 76-90.

Van Dyke CJ, Elias MJ. 2007. How forgiveness, purpose, and religiousity are related to the mental health and well-being of youth: A review of the literature. Mental Health, Religion and Culture 10: 395-415.

Wade NG, Hoyt WT, Kidwell JEM, Worthington EL. 2014. Efficacy of psychotherapeutic interventions to promote forgiveness: a Meta-Analysis. Journal of Counselling and Clinical Psychology 82: 154-170.

West, SG, Finch J, Curran PJ. 1995. Structural equation models with non-normal variables: Problems and remedies. In: Hoyle RH (ed.), Structural equation modeling: Concepts, issues and applications. Newbury Park: Sage. pp 56-75.

Wolke D, Woods S, Stanford K, Schulz H. 2001. Bullying and victimization of primary school children in England and Germany: Prevalence and school factors. British Journal of Psychology 92: 673-696.

Worthington EL, Scherer M. 2004. Forgiveness is an emotion-focused coping strategy that can reduce health risks and promote health resilience: theory, review and hypotheses. Psychology and Health 19: 385-405.

Worthington EL, Wade NG. 1999. The social psychology of unforgiveness and forgiveness and implications for clinical practice. Journal of Social and Clinical Psychology 18: 385-418.

Woods S, White E. 2005. The association between bullying behaviour, arousal levels and behavioural problems. Journal of Adolescence 28: 381-395. 